\title{
Helicobacter pylori Infection: Challenges in India
}

\author{
Ayaskanta Singh ${ }^{1 *}$ (D) Jimmy Narayan ${ }^{1}$ id and Shivaram Prasad Singh ${ }^{2}$
}

${ }^{1}$ Department of Gastroenterology, IMS and SUM Hospital, Siksha O Anusandhan, Deemed to be University, Bhubaneswar, Odisha, India. ${ }^{2}$ Department of Gastroenterology, S.C.B. Medical College, Cuttack - 753 007, Odisha, India.

\begin{abstract}
Helicobacter pylori (H. pylori) is a very common infection In India. Nevertheless there remain a lot of challenges with relation to this infection in this country. The lack of good clinical studies and absence of guidelines pertaining to the Indian sub continent makes dealing with this infection difficult. There is a lot of confusion whether to "test and treat" for $H$. pylori even in patients of peptic ulcer disease (PUD), un investigated dyspepsia, and those with high risk for gastric malignancy. Invasive and costly methods such as gastroscopy, rapid urease test (RUT) and biopsy are used to test $\boldsymbol{H}$. pylori. The noninvasive and cheap diagnostic tools such as breath tests and stool tests are not easily available in India. Once the diagnosis of $\boldsymbol{H}$. pylori infection is made, the next challenge is to determine the most effective antibiotic regimen in Indian context. Issues of antibiotic resistance and re infection make the management even more difficult. The Indian enigma of high $\mathbf{H}$. pylori infection and low gastric cancer(GC) rates makes the case against eradication even more strong. It is also important to consider the genetic diversity of $\boldsymbol{H}$. pylori in India. More long term prospective studies are required from India before we can take the eradication at community levels. Improvement of hygiene and sanitation and providing proper drinking water is a challenge that needs to be taken up by the health administration to deal with the $H$. pylori problem.
\end{abstract}

Keywords: Helicobacter pylori, dyspepsia, diagnosis; eradication; antibiotic resistance.

*Correspondence: ayaskant1ce@gmail.com; 9437155625

(Received: 23 March 2019; accepted: 10 June 2019)

Citation: Ayaskanta Singh, Jimmy Narayan and Shivaram Prasad Singh, Helicobacter pylori Infection: Challenges in India, J Pure Appl Microbiol., 2019; 13(2): 715-723. doi: 10.22207/JPAM.13.2.07

(c) The Author(s) 2019. Open Access. This article is distributed under the terms of the Creative Commons Attribution 4.0 International License which permits unrestricted use, sharing, distribution, and reproduction in any medium, provided you give appropriate credit to the original author(s) and the source, provide a link to the Creative Commons license, and indicate if changes were made. 


\section{INTRODUCTION}

Helicobacter pylori (H. pylori) is a gram negative bacterium. It colonises the mucosal lining of the human digestive tract. It has special affinity for stomach and duodenum ${ }^{1}$. Right from its discovery by Warren and Hastings in the early eighties; research on $H$. pylori is voluminous ${ }^{3,4}$. It is considered to be one of the most common chronic bacterial infections which affect almost two thirds of the worldwide population ${ }^{5}$. The transmission of this bacteria is from person to person and through contaminated water. It causes inflammation in the gut especially in the stomach and duodenum ${ }^{1}$. Most of these inflammatory changes are silent and clinical manifestations occur in around onefifth of the patients after a long latent period ${ }^{6} . \mathrm{H}$. pylori causes chronic active gastritis as a rule in almost all the patients. Studies have shown that this infection has a role in causing peptic ulcer disease(PUD), atrophic gastritis, gastric neoplasm, and "mucosa-associated lymphoid tissue(MALT)" lymphoma ${ }^{1,7,8}$.

There is a steady decline in the incidence of $H$. pylori infection. This has been attributed to the facts that there has been improvement in hygiene and sanitation and also due to development of antibiotic regimens which can successfully eradicate the infection. Nonetheless in a country like India; a lot of challenges remain. The need of the hour is to consider $H$. pylori is a serious transmissible infectious disease, to discuss the pros and cons of treating this infection as a whole or in a select group of patients. It is pertinent to consider the genomic profile and variants of $H$. pylori in India. Focus should be on the regional data on antibiotic resistance profile and the effectiveness of the various antibiotic regimens in eradicating the bacterium. The unawareness of general physicians regarding the infection; the apathy of the health care system and the absence of guidelines especially from India makes it more challenging to deal with this infectious disease.

\section{H. pylori and its significance in India}

H. pylori is a very common infection. It's sero prevalence varies from $5-10 \%$ in developed countries to $80-90 \%$ in the developing countries ${ }^{9}$. The story is no different in the Indian subcontinent. Most of the cases are exposed to the infection in childhood and approximately eighty per cent of the general population is infected when they reach adulthood ${ }^{9}$. Various epidemiological surveys indicate a "sero prevalence of $20 \%-50 \%$ in children under the age of five, increasing to $80 \%-90 \%$ by the age of twenty, and remaining constant thereafter" $"$-11. This infection is transmitted by feco oral route. Contaminated water is often the culprit in causing this infection especially in the rural areas ${ }^{12,13}$. Hygiene plays a major role in the prevalence of this infection. This has been reflected in the fact that in developed countries and in societies with improved sanitation; there has been notable drop in the prevalence of this infection ${ }^{8}$. The reasons behind the commonness of this infection and lower age of acquisition in India are poverty, overcrowding, poor sanitation and contaminated water supply. This is a massive challenge from the administrative point of view to improve the general health; hygiene and sanitation and provide good drinking water in order to prevent this infection.

The infection primarily causes inflammation of the mucosa of stomach and duodenum. The inflammation may have acute changes such as gastritis; yet the most clinical significant manifestations are usually long standing. It may cause numerous manifestations such as atrophic gastritis; intestinal metaplasia; PUD; gastric lymphoma and neoplasms ${ }^{1,7-8}$. The infection has also been implicated to cause iron deficiency anemia; idiopathic thrombocytopenia and vitamin B12 deficiency ${ }^{14-16}$. However many clinicians also consider $\mathrm{H}$. pylori as an innocent bystander whose eradication may cause more harm than good.

The most significant outcome of $H$. pylori infection is gastric neoplasm ${ }^{2-3}$. There is a lot of research papers including meta analysis which established that $H$. pylori is an important cause for gastric neoplasm ${ }^{2-3}$. However in some regions of the world [Africa and Indian sub continent]; there is very high infection rates of $H$. pylori; yet fortunately the prevalence of gastric malignancy is low. On the other hand, the prevalence of $H$. pylori related peptic ulcer disease and its complications are quite high in these regions.

Should $\boldsymbol{H}$. pylori be eradicated in Indian setting?

Although the clinical implication of this infection is huge; the most significant being gastric malignancies; yet it is improbable to screen and eradicate $H$. pylori on mass population especially in 
a country like India. Ramakrishna BS in an excellent review article has discussed elaborately the points why H. pylori infection should not be eradicated in India ${ }^{17}$.

"Maastricht V/Florence Consensus Report" recommend that " $H$. pylori eradication for gastric cancer prevention is cost-effective in communities with a high risk for gastric cancer"18. The "Second Asia-Pacific consensus guidelines for H. pylori infection" also advocates similar strategy of universal eradication of $H$. pylori at community levels ${ }^{19}$. These recommendations are based on the community based economic studies that have evaluated the cost-effectiveness of "screenand-treat" policies in general population for the prevention of gastric neoplasms ${ }^{20}$. This approach will benefit those communities, who have a high prevalence of gastric cancer(GC). Almost all the randomized trials favoring mass eradication were conducted in these areas. However in countries like India where the prevalence of GC is low; long term longitudinal studies are required to gauge the cost effectiveness of such a strategy of mass eradication. Indian authors argue that adopting such a practice in India is challenging and not viable $^{17,20}$.

The estimated population of the country is just about 1.3 billion people. If we keep the H. pylori prevalence at $60 \%$, roughly around 8 hundred million individuals will have $H$. pylori infection ${ }^{21}$. The enormity of the task of treating this infection at community levels is discouraging and might dissuade doctors and the government from aggressively managing the infection. Nonetheless, when one considers it on an individual case basis, it becomes much simpler to deal with the problem.

There is another aspect of $H$. pylori infection. The $H$. pylori strains are genetically variable, and there are certain known markers of virulence in $\mathrm{H}$. pylori. The virulence factors, which have been recognized are the "cag pathogenicity island (cag PAI)", the "vacuolating cytotoxin (VacA)" and the "outer inflammatory protein (Oip A)". It is likely that all individuals do not have infection with the virulent strains of $H$. pylori. Host genetic predisposition and environmental factors plays an important role in the expression of various manifestations of $H$. pylori. This probably can explain low prevalence of gastric carcinoma in Indian sub continent. However the challenge is to identify the various virulent strains of $H$. pylori in India and treat accordingly. Some authors consider H. pylori a normal commensal rather than a pathogen in human beings. They consider $\mathrm{H}$ pylori to be protective against certain immunological and autoimmune diseases like asthma and Crohn's disease $^{22}$. Any indiscriminate eradication may do more harm than good. Thus the biggest question is that whether $H$ pylori infection needs eradication and who are the patient groups who should be treated.

The American College of Gastroenterology (ACG) guideline says that "all patients with a positive test of active infection with $\mathrm{H}$. pylori should be offered treatment ${ }^{\prime \prime 23}$. Thus the crucial issue is to identify the patients who should be tested? Hence the following specific conditions are discussed in detail.

\section{Peptic ulcer disease [ PUD]}

One important indication for treatment of H. pylori infection is PUD. Studies from various parts of the country have shown a strong association of this bacteria with duodenal and gastric ulcers ${ }^{24-25}$. Many papers from the West showed that treatment of this infection not only caused ulcer healing, but also prevented ulcer recurrenc ${ }^{26-27}$. However peptic ulcer can occur again if there was recurrence (either recrudescence or re-infection). Marshall et al in their landmark paper concluded that " $H$. pylori eradication resulted in greater peptic ulcer healing rate ( $92 \%$ vs. $61 \%)$ and lower 12 -month relapse rate ( $21 \%$ vs. $84 \%$ ) than non-eradication" 26 . A meta-analysis which included thirty four studies involving around four thousand patients, eradication therapy with antibiotics was superior to proton pump inhibitors alone in healing duodenal ulcer and better to placebo in avoidance of ulcer recurrence ${ }^{27}$.

Indian studies also show a good duodenal ulcer healing [75\%-90\%] with antibiotic therapy intended to treat $H$. pylori infection ${ }^{28-29}$. However the problem in India is that the relapse rates of peptic ulcer after eradication therapy is higher than those reported in studies reported from the West. Nanivadekar et al had followed up patients with healed duodenal ulcer for three years. They 
found that ulcer relapse was seen around $10 \%$ of cases without recurrence of $H$. pylori infection and in $63 \%$ cases with recurrence of $H$. pylori infection ${ }^{30}$

\section{Non-ulcer dyspepsia [NUD] and un investigated dyspepsia}

H. pylori gastritis is considered to be a cause of dyspepsia. However the majority of studies on functional dyspepsia have not shown any benefit after eradication of $H$. pylori infection. A Cochrane Database review of seventeen randomized controlled trials that looked into over three thousand patients concluded that "there was an $8 \%$ relative risk reduction in dyspeptic symptoms after $H$. pylori eradication" ${ }^{\prime 3}$. Thus there is very small benefit in treating dyspepsia with antibiotics. The few studies from India also echo similar results. Different studies from the country showed that treatment of $H$. pylori is not that effective as compared to PPI s; sucralfate or anti depressants in providing symptomatic relief in NUD patients ${ }^{32-33}$.

Several guidelines on $H$. pylori now advocate a "test-and treat" in primary care without doing a gastroscopy $y^{18-19,23}$. The recommendations suggest that those patients who are under the age of fifty and without any alarm symptoms; should be tested and treated if positive for $H$. pylori; rather than doing invasive procedure like an endoscopy ${ }^{23}$. However the evidences from India are not substantial enough for adapting such a practice. Even a Cochrane Database systematic review concluded that such a test and treat approach is not cost effective in primary care setting and also does not provide symptomatic relief in dyspeptic patients ${ }^{31}$.

\section{Gastric Carcinoma and the Indian Enigma}

H. pylori is being recognized as Type I carcinogen for GC and primary gastric lymphoma(GL). There is substantial evidence in form of meta analyses of case control studies which suggest $H$ pylori can cause both $\mathrm{GC}$ and $\mathrm{GL}^{34-}$ ${ }^{36}$. However most of the data supporting this have come from case control studies from countries like Japan and China where there is a high prevalence of gastric neoplasm. In Asian countries like India and similar tropical countries from Africa there exists incongruence between the $H$. pylori infection rates and gastric malignancies. In our country even if there is a very high frequency of $H$. pylori infection; yet incidence of gastric neoplasm is relatively low. Probably other factors apart from the infection, play a role in the etiopathogenesis of GC. Indian diet may also act as a protective factor against the dreaded malignancy. Even within the country there is great regional variation with respect to infection and the prevalence of GC. There is a lack of good studies from India. There are few case control studies and unexpectedly they failed to show an association between $H$. pylori infection and GC. Kate $\mathrm{V}$ et al have done case control study where 50 patients with gastric neoplasms and 50 controls with non-ulcer dyspepsia (NUD) were enrolled. They found that $H$. pylori infection was detected less commonly in GC (38\%) than those with NUD $(68 \%)^{37}$. Another study from South India showed that $64.7 \%$ patients with gastric adenocarcinoma and $74.4 \%$ patients with NUD tested positive for $H$. pylori ${ }^{38}$. However these studies had very small sample size and the results cannot be extrapolated to the general Indian population. Another limitation of the above cited studies is that gastroscopy based rapid urease tests (RUT) were used to diagnose $H$. pylori infection. The problem with these endoscopy-based tests is that in patients with $\mathrm{GC}$ due to presence of underlying gastric atrophy and intestinal metaplasia, the tests can be false negative. Another case control study from Lucknow had taken a better sample size of 279 cases with gastric neoplasms (263 GCs and $16 \mathrm{GLS})$ and 456 healthy controls. This study also failed to demonstrate that $H$. pylori infection was more common in patients with gastric neoplasm as compared to the controls ${ }^{39}$. Thus research from India on this infection and its association with gastric neoplasm and its premalignant conditions like intestinal metaplasia and atrophic gastritis is really scarce to derive any definitive conclusion.

Diagnosis of $\boldsymbol{H}$. pylori infection: Difficulties faced in India

The initial stage in the management is to establish the diagnosis of $H$. pylori infection. The challenges that doctors face in India are issues of accessibility and expenditure with regards to the diagnostic tests of $H$. pylori infection. Worldwide, non invasive tests for active infection are preferred (e.g., "urea breath test" or "stool antigen test") over tests that require endoscopy. Although, the 14C-urea breath test is probably the cheapest test, yet it is not readily available. Endoscopy is available 
at tertiary care centers, but is high-priced. The cost can range from Rs 300 at a government hospital or medical college to between Rs 500 and Rs 5000 at corporate hospitals and diagnostic centers ${ }^{40}$. The advantage of endoscopy is that patients can be evaluated for mucosal disease such as peptic ulcers, gastritis and early malignancy. Endoscopy also allows one to take biopsy specimens that can be examined by histopathology, "rapid urease test (RUT)", or culture for antibiotic sensitivity. RUTs are inexpensive, accurate and easily available. Saksena et al showed that "the rapid urease test (RUT) and brush cytology had the highest degree of agreement whereas histology was the most specific diagnostic test" ${ }^{\prime 1}$. Another major issue with endoscopy is that most of the hospitals and diagnostic centres do not follow the standard protocol of disinfection of the endoscope. Essentially, the endoscope, the biopsy forceps, and other parts of the endoscopy system can easily become infected with $H$. pylori and can spread the infection. Thus it is essential to maintain high-level disinfection of all endoscopic equipments in order to prevent the iatrogenic spread of the infection.

Serologic testing for $H$. pylori antibodies has $>80$ per cent sensitivity and $>90$ per cent specificity. This test is easily available but is costly. Another limitation of the test is that even after successful eradication of $\mathrm{H}$ pylori, it can remain positive for many years. All the recommendations do not advocate serologic testing for diagnosing this infection.
Challenges faced in H. pylori eradication in India

There are two important reasons why $H$. pylori treatment is a challenge in the Indian sub continent. First, the surroundings and water is contaminated and the gut infections are very widespread. This may make the task of eradication of this infection futile if there is going to be reinfection with the same bacteria sooner or later. Secondly, antibiotic use is widely prevalent. In India, antibiotics are easily available, even without a prescription and this easy access can lead to overuse or misuse. Even doctors are sometimes at fault as antibiotics are commonly misprescribed or dispensed erroneously due to lack of apt awareness, desire to meet patient demands and maybe for economic incentives. This results in high frequency of antibiotic resistance.

Table 1 shows the high percentage of antibiotic resistance from various studies from India. This implies that the standard antibiotics regimens for $H$. pylori infection may not be effective in India. Fixed dose combinations(FDC) of proton pump inhibitors [PPIs] and antibiotics which are cost effective and easy to prescribe, are widely available in India. One such FDC of PPI with amoxicillin and tinidazole is very popular and widely prescribed by Indian doctors. However; in these FDCs, the dose of amoxicillin is suboptimal, being $750 \mathrm{mg}$ BID rather than $1 \mathrm{~g}$ BID as recommended. In a large Indian multicentre study by Thyagarajan et al, two fifty nine isolates of $H$. pylori were tested for susceptibility to antibiotics in vitro. They found

Table 1. H. pylori antibiotic resistance in India

\begin{tabular}{lccc}
\hline Antibiotic & Study & $\begin{array}{c}\text { Number of } \\
\text { patients }\end{array}$ & $\begin{array}{c}\text { Resistance } \\
\text { rate (\%) }\end{array}$ \\
\hline 1. Clarithromycin & Thyagarajan $^{42}$ & 259 & 45 \\
& Mhaskar $^{48}$ & 15 & 91 \\
2. Amoxicillin & Abraham $^{49}$ & 7 & 100 \\
& Thyagarajan $^{42}$ & 259 & 33 \\
3. Tetracycline & Devarbhavi $^{50}$ & $\sim$ & 40 \\
4. Metronidazole & Mhaskar $^{48}$ & 15 & 73 \\
& Datta $^{43}$ & 67 & 8 \\
& Mhaskar $^{48}$ & 15 & 27 \\
& Datta $^{43}$ & 67 & 85 \\
Bhatia $^{45}$ & 31 & 42 \\
& Thyagarajan $^{42}$ & 259 & 78 \\
Journal of Pure and Applied & Microbiology & $\sim$ & 90 \\
& Mukhopadhyay & $\sim$ &
\end{tabular}


that "around $80 \%$ had resistance to metronidazole, $45 \%$ to clarithromycin, and 33\% to amoxicillin" 42 In another study from West Bengal, $80 \%$ and $8 \%$ of the bacteria were resistant to metronidazole and tetracycline respectively ${ }^{43}$. In a similar study from Gujrat, around $80 \% \mathrm{H}$. pylori isolates were resistant to metronidazole, around $60 \%$ were resistant to Clarithromycin and around $70 \%$ were resistant to Amoxicillin, 50\% to Ciprofloxacin and 50\% to tetracycline ${ }^{44}$. Thus the fixed-drug combinations used to eradicate the infection may be less useful in view of such high antibiotic resistance in India.
The effectiveness of various antibiotic regimens in treating $H$. pylori needs to be determined in Indian setting. The few clinical studies from India which have been done on the eradication rate of the bacteria are discussed in Table 2. The problem with many of these trials is that they used a single test (RUT) to establish the clearance of $H$. pylori bacteria. When rigorous criteria (i.e., "a combination of negative urease test, negative histology and negative urea breath test") were applied; the eradication rate was significantly lower. In a clinical trial done by Bhatia

Table 2. Eradication Rates of H. pylori in India

\begin{tabular}{|c|c|c|c|c|c|c|}
\hline & $\begin{array}{c}\text { Number of } \\
\text { patients }\end{array}$ & Location & $\begin{array}{c}\text { Treatment } \\
\text { regimen }\end{array}$ & Duration & $\begin{array}{l}\text { Eradication } \\
\text { Rates }\end{array}$ & $\begin{array}{l}\text { Tests } \\
\text { used }\end{array}$ \\
\hline Valooran et al. ${ }^{51}$ & 73 & Pondicherry & $\begin{array}{l}\text { Omeprazole; } \\
\text { Clarithromycin } \\
\text { Amoxicillin }\end{array}$ & 10 days & $81 \%$ & $\begin{array}{c}\text { RUT; } \\
\text { Histology }\end{array}$ \\
\hline Chaudhary et al. ${ }^{52}$ & 20 & New Delhi & $\begin{array}{l}\text { Lansoprazole; } \\
\text { Amoxicillin } \\
\text { Tinidazole }\end{array}$ & 14 days & $80 \%$ & RUT \\
\hline Bhatia et al. ${ }^{45}$ & 70 & Mumbai & $\begin{array}{c}\text { Lansoprazole; } \\
\text { Amoxicillin } \\
\text { Tinidazole }\end{array}$ & 14 days & $42 \%$ & $\begin{array}{c}\text { RUT; } \\
\text { UBT; } \\
\text { Histology }\end{array}$ \\
\hline Bhasin et al. ${ }^{53}$ & 20 & Chandigarh & $\begin{array}{l}\text { Omeprazole; } \\
\text { Clarithromycin } \\
\text { Amoxicillin }\end{array}$ & 14 days & $70 \%$ & RUT; \\
\hline Bhasin et al. ${ }^{54}$ & 24 & Chandigarh & $\begin{array}{l}\text { Lansoprazole; } \\
\text { Amoxicillin } \\
\text { Clarithromycin }\end{array}$ & 14 days & $96 \%$ & RUT \\
\hline
\end{tabular}

et al. around 150 patients were randomized either to receive lansoprazole, amoxicillin and tinidazole or lansoprazole, amoxicillin and clarithromycin. Surprisingly it was found that "only $31 \%$ and $46 \%$ of patients receiving the above combinations respectively had eradication of $H$. pylori infection" ${ }^{45}$.

It is a major challenge to diagnose complete $H$. pylori eradication. All the guidelines suggest $\mathrm{H} 2$ breath test as the gold standard test to look for $H$. pylori eradication. However limited availability of the breath test makes it a Herculean task. On the other hand, it is very difficult to convince a patient to undergo a costly and invasive test such as gastroscopy and RUT test for the second time.
Another point to consider is that it is likely that the rates of recurrence of the infection, after successful treatment, may be very high in India. Studies from the West show that re-infection rates are very low $(<0.5$ per patient year) after successful eradication ${ }^{46}$. However there are only few papers on $H$. pylori recurrence rates after successful eradication from India. In one study of forty five patients who were followed up for one year following successful eradication of $H$. pylori, it was seen that recurrence of infection was observed in only one case $(2.4 \%)^{47}$. However, the study by Nanivadekar et al from India show that recurrence of $H$. Pylori occurs in around $60 \%$ of patients within 3 years ${ }^{30}$. 


\section{CONCLUSION}

There remain a lot of challenges with relation to $H$. pylori infection in India. There is lack of good clinical studies from India and absence of guidelines pertaining to the Indian sub continent. There is a lot of confusion whether to "test and treat" for $H$. pylori even in patients of peptic ulcer disease, un investigated dyspepsia, and those with high risk for gastric malignancy. Invasive and costly methods such as gastroscopy and RUT and biopsy are used to test $H$. pylori. The non invasive and cheap diagnostic tools such as breath tests and stool tests are not easily available in India. Once the identification of $H$. pylori infection is made, the next challenge is to determine the most effective antibiotic regimen in Indian context. Issues of antibiotic resistance and re infection make the management even more difficult. The Indian enigma of high $\mathrm{H}$. pylori infection and low incidence of $\mathrm{GC}$ makes the case against eradication of $H$. pylori even more strong. As $H$. pylori strains are genetically diverse, it is unlikely that most infected persons in the community have virulent strains. More long term prospective studies are required from India before we can take the eradication at community levels. Improvement of hygiene and sanitation and providing proper drinking water is a challenge that needs to be taken up by the health administration to deal with the H. pylori problem.

\section{ACKNOWLEDGEMENTS}

None.

\section{CONFLICT OF INTEREST}

The authors declares that there is no conflict of interest.

\section{AUTHORS' CONTRIBUTION}

AS and JN drafted the manuscript. JN gathered information from the literature. AS compiled information from the literature, and designed the figures and tables. SP supervised and reviewed the manuscript.

\section{FUNDING}

None.

\section{DATA AVAILABILITY}

All datasets generated or analyzed during this study are included in this review.

\section{ETHICS STATEMENT}

This article does not contain any studies with human participants or animals performed by any of the authors.

\section{REFERENCES}

1. Axon A., Forman D. Helicobacter gastroduodenitis: a serious infectious disease. BMJ, 1997; 314: 1430-1.

2. Graham D. Y. Helicobacter pylori infection in the pathogenesis of duodenal ulcer and gastric cancer: a model. Gastroenterology, 1997; 113(6): 1983-91.

3. Marshall B. J., Warren J. R. Unidentified curved bacilli in the stomach of patients with gastritis and peptic ulceration. Lancet, 1984; 1: 1311-1315

4. Mitchell H., Katelaris P. Epidemiology, clinical impacts and current clinical management of Helicobacter pylori infection. The Medical Journal of Australia, 2016; 204(10): 376-80.

5. Brown L. M. Helicobacter pylori: epidemiology and routes of transmission. Epidemiologic Reviews. 2000; 22(2): 283-97.

6. Go M. F. Natural history and epidemiology of Helicobacter pylori infection. Alimentary Pharmacology \& Therapeutics, 2002; 16: 3-15.

7. Nakamura S., Sugiyama T., Matsumoto T., lijima K., Ono S., Tajika M., Tari A., Kitadai Y., Matsumoto H., Nagaya T., Kamoshida T. Long-term clinical outcome of gastric MALT lymphoma after eradication of Helicobacter pylori: a multicentre cohort follow-up study of 420 patients in Japan. Gut., 2012; 61(4): 507-13.

8. Graham D. Y., Adam E., Reddy G. T., Agarwal J. P. Seroepidemiolody of $\mathrm{H}$. pylori infection in India: Comparison of developing and developed countries. Dig. Dis. Sci., 1991; 36: 1084-8.

9. Gill H. H., Majumdar P., Shankaran K., Desai H. G. Agerelated prevalence of $\mathrm{H}$. pylori antibodies in Indian subjects. Indian J. Gastroenterol., 1994; 13: 92-4.

10. Kang G., Rajan D. P., Patra S., Chacko A., Mathan M. M. Use of serology, the urease test and histology in diagnosis of $\mathrm{H}$. pylori infection in symptomatic and asymp-tomatic Indians. Indian J. Med. Res., 1999; 110: 86-90.

11. Jais M., Barua S. Seroprevalence of anti H. pylorilgG/ IgA in asymptomatic population from Delhi. J. Commun Dis., 2004; 36: 132-5.

12. Ahmed K. S., Khan A. A., Ahmed I., Tiwari S. K., Habeeb A., Ahi J. D., Abid Z., Ahmed N., Habibullah C. M. Impact of household hygiene and water source on the prevalence and transmission of Helicobacter pylori: a South Indian perspective. Singapore Medical Journal, 2007; 48(6): 543-9

13. Nurgalieva Z. Z., Malaty H. M., Graham D. Y., Almuchambetova R., Machmudova A., Kapsultanova D., Osato M. S., Hollinger F. B., Zhangabylov A. Helicobacter pylori infection in Kazakhstan: effect of 
water source and household hygiene. The American Journal of Tropical Medicine and Hygiene, 2002; 67(2): 201-6.

14. Queiroz D. M., Harris P. R., Sanderson I. R., Windle H. J., Walker M. M., Rocha A. M., Rocha G. A., Carvalho S. D., Bittencourt P. F., de Castro L. P., Villagran A. Iron status and Helicobacter pylori infection in symptomatic children: an international multi-centered study. PLOS One, 2013; 8(7): e68833.

15. Sato R., Murakami K., Okimoto T., Watanabe K., Kodama M., Fujioka T. Development of corpus atrophic gastritis may be associated with Helicobacter pylorirelated idiopathic thrombocytopenic purpura. Journal of Gastroenterology, 2011; 46(8): 991-7.

16. Qu X. H., Huang X. L., Xiong P., Zhu C. Y., Huang Y. L., Lu L. G., Sun X., Rong L., Zhong L., Sun D. Y., Lin H. Does Helicobacter pylori infection play a role in iron deficiency anemia? A meta-analysis. World Journal of Gastroenterology: WJG. 2010; 16(7): 886-96

17. Ramakrishna B. S. H. pylori infection in India: the case against eradication. Indian Journal of Gastroenterology, 2006; 25(1): 25.

18. Malfertheiner P., Megraud F., O'morain C. A., Gisbert J. P., Kuipers E. J., Axon A. T., Bazzoli F., Gasbarrini A., Atherton J., Graham D. Y., Hunt R. Management of Helicobacter pylori infection-the Maastricht V/ Florence consensus report. Gut., 2017; 66(1): 6-30.

19. Fock K. M., Katelaris P., Sugano K., Ang T. L., Hunt R., Talley N. J., Lam S. K., Xiao S. D., Tan H. J., Wu C. Y., Jung H. C. Second Asia-Pacific consensus guidelines for H. pylori infection. Journal of Gastroenterology and Hepatology,. 2009; 24(10): 1587-600.

20. Thirumurthi S., Graham D. Y. H. pylori infection in India from a western perspective. The Indian Journal of Medical Research, 2012; 136(4):549.

21. State. gov. Available from: http://www. state. gov/r/ pa/ei/bgn/3454. htm, accessed on October 14, 2016

22. Bach J. F. The effect of infections on susceptibility to auto immune and allergic diseases. N. Engl. J. Med., 2002; 347: 91120.

23. Chey W. D., Leontiadis G. I., Howden C. W., Moss S. F. ACG clinical guideline: treatment of $\mathrm{H}$. pylori infection. The American journal of gastroenterology,. 2017; 112(2): 212.

24. Panigrahi M. K., Singh A., Uthansingh K., et al. Clinical Profile and Risk factor of Peptic ulcer disease in coastal eastern India. Journal of Medical Science And clinical Research, 2018; 06(7): 615-620

25. Prasad S., Mathan M., Chandy G., Rajan D. P., Venkateswaran S., Ramakrishna B. S., et al. Prevalence of $\mathrm{H}$. pylori in southern Indian controls and patients with gastroduode-nal disease. J. Gastroenterol Hepatol., 1994; 9:501-6.

26. Marshall B., Warren J. R., Blincow E., Phillips M., Goodwin C. S., Murray R., Blackbourn S., Waters T., Sanderson C. Prospective double-blind trial of duodenal ulcer relapse after eradication of Campylobacter pylori. The Lancet, 1988; 332(86268627): 1437-42.

27. Ford A. C., Delaney B., Forman D., Moayyedi P. Eradication therapy for peptic ulcer disease in Helicobacter pylori positive patients. Cochrane
Database of Systematic Reviews. 2006(2).

28. Dayal V. M., Kumar P., Kamal J., Shahi S. K., Agrawal B. $\mathrm{K}$. Triple-drug therapy of $\mathrm{H}$. pylori infection in duodenal ulcer disease. Indian J Gastroenterol., 1997; 16: 46-8.

29. Ahuja V., Dhar A., Bal C., Sharma M. P. Lansoprazole and secnidazole with clarithromycin, amoxycillin or pefloxacin in the eradication of $\mathrm{H}$. pylori in a developing country. Aliment Pharmacol. Ther.,1998; 12: 551-5.

30. Nanivadekar S. A., Sawant P. D., Patel H. D., Shroff C. P., Popat U. R., Bhatt P. P. Association or peptic ulcer with $\mathrm{H}$. pylori and the recurrence rate. A three year follow up study. J Assoc Physicians India 1990;38 (Suppl 1):703-6

31. Moayyedi P., Soo S., Deeks J., Delaney B., Harris A., Innes M., Oakes R., Wilson S., Roalfe A., Bennett C., Forman D. Eradication of Helicobacter pylori for non ulcer dyspepsia. Cochrane Database of Systematic Reviews. 2005(2).

32. Dhali G. K., Garg P. K., Sharma M. P. Role of anti-H. pylori treatment in $\mathrm{H}$. pylori-positive and cytoprotective drugs in $\mathrm{H}$. pylori-negative, non-ulcer dyspepsia: results of a randomised, double-blind, controlled trial in Asian Indi ans. J. Gastroenterol. Hepatol., 1999; 14: 523-8.

33. Singh S. P., Thatoi P. K., Mohanty C. B. K. et al. The role of H. pylori in non ulcer dyspepsia(NUD) Indian J. Gastroenterol., 1997; 16(Suppl 1): S53.

34. Xue F. B., Xu Y. Y., Wan Y., Pan B. R., Ren J., Fan D. $M$. Association of $\mathrm{H}$ pylori infection with gastric carcinoma: a Meta analysis. World J. Gastroenterol., 2001; 7: 801-804

35. Eslick G. D., Lim L. L., Byles J. E., Xia H. H., Talley $\mathrm{N}$. J. Association of $\mathrm{H}$. pylori infection with gastric carcinoma: a metaanalysis. Am. J. Gastroenterol., 1999; 94: 2373-2379.

36. Ford A. C., Forman D., Hunt R., Yuan Y., Moayyedi P. Helicobacter pylori eradication for the prevention of gastric neoplasia. Cochrane Database of Systematic Reviews. 2015(7).

37. Kate V., Ananthakrishnan N. H. pylori and gastric carcinoma: evidence for the link. Natl. Med. J. India, 2000; 13: 329.

38. Khanna A. K., Seth P., Nath G., Dixit V. K., Kumar M. Correlation of $\mathrm{H}$. pylori and gastric carcinoma. J. Postgrad. Med., 2002; 48: 27-28

39. Ghoshal U. C., Tiwari S., Pandey R., Dhingra S., Ghoshal U., Singh H., Nagpal A. K., Gupta V. K., Naik S., Ayyagari A. Frequency of Helicobacter pylori and CagA antibody in patients with gastric neoplasms and controls: The Indian enigma. Am. J. Gastroenterol., 2005; 100: S64

40. Bhatia S. J., Kulkarni S. G. Cost-effectiveness of H. pylori eradication in India: to live and let live. expensively? Indian J. Gastroenterol., 1997; 16 (Suppl 1): S25-8.

41. Saksena S., Dasarathy S., Verma K., Ahuja V., Sharma M. P. Evaluation of endoscopy-based diagnostic methods for the detection of Helicobacter pylori. Indian J. Gastroenterol., 2000; 19: 61-3.

42. Thyagarajan S. P., Ray P., Das B. K., Ayyagari A., Khan A. A., Dharmalingam S., Rao U. A., Rajasambandam P., Ramathilagam B., Bhasin D., Sharma M. P. Geographical difference in antimicrobial resistance pattern of Helicobacter pylori clinical isolates from 
Indian patients: Multicentric study. Journal of Gastroenterology and Hepatology, 2003; 18(12): 13738.

43. Datta S., Chattopadhyay S., Patra R., De R., Ramamurthy T., Hembram J., Chowdhury A., Bhattacharya S. K., Berg D. E., Nair G. B., Mukhopadhyay A. K. Most Helicobacter pylori strains of Kolkata in India are resistant to metronidazole but susceptible to other drugs commonly used for eradication and ulcer therapy. Alimentary Pharmacology \& Therapeutics, 2005; 22(1):51-7.

44. Pandya H. B., Agravat H. H., Patel J. S., Sodagar N. R. Emerging antimicrobial resistance pattern of Helicobacter pylori in central Gujarat. Indian Journal of Medical Microbiology, 2014; 32(4): 408.

45. Bhatia V., Ahuja V., Das B., Bal C., Sharma M. P. Use of imidazole based eradication regimens for Helicobacter pylori should be abandoned in North India regardless of In vitro antibiotic sensitivity. Journal of Gastroenterology and Hepatology, 2004; 19(6):619-25.

46. Borody T. J., Andrews P., Mancuso N., McCauley D., Jankiewicz E., Ferch N., Shortis N. P., Brandl S. Helicobacter pylori reinfection rate, in patients with cured duodenal ulcer. American Journal of Gastroenterology, 1994; 89(4).

47. Bapat M. R., Abraham P., Bhandarkar P. V., Phadke A. Y., Joshi A. S. Acquisition of $H$. pylori infection and reinfection after its eradication are uncommon in Indian adults. Indian J Gastroenterol., 2000; 19: 172-4.

48. Mhaskar M., Sandhu N., Abraham P. In vitro antimicrobial susceptibility of $H$. pylori in Indian patients. Indian J. Gastroenterol., 1997; 16(Suppl 1): S53.

49. Abraham P., Sandhu N., Naik S. R. In vitro sensitivity of H. pylori in India. Indian J. Gastroenterol., 1997; 16(Suppl 1): S20-1.

50. Devarbhavi H., Nanivadekar S., Sawant P., Saraswathy K. Sensitivity of $H$. pylori isolates from Indian patients to different antibacterial agents. Indian J Gastroenterol., 1998; 17(Suppl 1): S53.

51. Valooran G. J., Kate V., Jagdish S., Basu D. Sequential therapy versus standard triple drug therapy for eradication of $H$. pylori in patients with perforated duodenal ulcer following simple closure. Scand. J. Gastroenterol., 2011; 46: 1045-50.

52. Chaudhary A., Ahuja V., Bal C. S., Das B., Pandey R. M., Sharma M. P. Rank order of success favors longer duration of imidazole-based therapy for $\mathrm{H}$. pylori in duodenal ulcer disease: a randomized pilot study. Helicobacter, 2004; 9: 124-9.

53. Bhasin D. K., Sharma B. C., Ray P., Pathak C. M., Singh K. Comparison of seven and fourteen days of lansoprazole, clarithromycin, and amoxicillin therapy for eradication ofHelicobacter pylori: a report from India. Helicobacter, 2000; 5: 84-7.

54. Bhasin D. K., Sharma B. C., Sinha S. K., Ray P., Vaiphei K., Singh K. Helicobacter pylori eradication: comparison of three treatment regimens in India. J. Clin. Gastroenterol., 1999; 28: 348-51. 